\title{
Body Language as a Communicative Aid amongst Language Impaired Students: Managing Disabilities
}

\author{
Nnenna Gertrude Ezeh ${ }^{1}$, Ojel Clara Anidi ${ }^{2} \&$ Basil Okwudili Nwokolo ${ }^{1}$ \\ ${ }^{1}$ The Use of English Unit, School of General Studies, University of Nigeria, Nsukka (Enugu Campus), Nigeria \\ ${ }^{2}$ Department of Language Studies, School of General Studies, Institute of Management and Technology, Enugu, \\ Nigeria \\ Correspondence: Nnenna Gertrude Ezeh, C/o Department of Theology, Bigard Seminary Enugu. P.O. Box 327, \\ Uwani- Enugu, Nigeria.
}

Received: April 10, 2021

Accepted: May 28, 2021

Online Published: May 31, 2021

doi: 10.5539/elt.v14n6p125

URL: https://doi.org/10.5539/elt.v14n6p125

\begin{abstract}
Language impairment is a condition of impaired ability in expressing ideas, information, needs and in understanding what others say. In the teaching and learning of English as a second language, this disability poses a lot of difficulties for impaired students as well as the teacher in the pedagogic process. Pathologies and other speech/language interventions have aided such students in coping with language learning; however, this study explores another dimension of aiding impaired students in an ESL situation: the use of body language. The study adopts a quantitative methodology in assessing the role of body language as a learning tool amongst language/speech impaired students. It was discovered that body language aids students to manage speech disabilities and to achieve effective communication; this helps in making the teaching and learning situation less cumbersome.
\end{abstract}

Keywords: body language, communication, language and speech impairment, English as a second language

\section{Introduction}

\subsection{Introduction}

In communication, words are inadequate. Neil Postman, a writer about language and education, opines that in a language environment, four elements are involved - people, their purpose, the rules of communication by which they achieve their purpose and the actual words being used in the situation (Verderber \& Verdeber, 2005).

Communication is therefore any process by which people share information, ideas and feelings through spoken and written words ,body language, personal mannerism and style, the physical environment- anything that adds meaning (wiki/comunication.org). In other words, certain verbal information are facilitated by the use of gestural communication such as facial expressions, body movements, eye gaze, body postures and the like. All these fall under the use of body language, otherwise known as kinesis. The use of body language amongst language learners is a sine qua non to learning, especially amongst students who are language and speech impaired.

Language and speech impairment are used interchangeably in most cases, but language impairment is more embracing; as it incorporates certain speech disorders (expressive disorders) as well as difficulty in understanding what others are saying (receptive disorders). Speech impairment on the other hand refers to an impaired ability to produce speech sounds. These are usually characterised by stuttering and other articulation disorders (Hybels \& Weaver, 1998).

In this study, both types of disorders are incorporated and used interchangeably, while body language is proffered as a learning aid in both situations. Speech impairment at every stage can lead to social isolation, embarrassment and language disabilities. More importantly, this condition can pose serious obstacles for the affected learners in language learning. The study therefore tries to establish the significant role that body language plays in language teaching and learning, especially in the ESL context. 


\subsection{Aim}

The study has two aims. First, to analyse the role of body language in the teaching and learning of the English language and second, to establish the importance of body language in communication amongst speech impaired students in an ESL context.

\subsection{Significance of the Study}

The research is significant in many ways. First, it will help in bridging the gap between disability and language acquisition amongst language impaired students.

It will also establish the vital role of communication in managing disabilities, especially in the teaching and learning context. Additionally, the study will instil confidence amongst language impaired students, as they will learn at the same pace with their colleagues using the medium of body language; also the speech impaired students will have the opportunity to effectively communicate with others.

\section{Material Studied}

\subsection{Communication}

Essentially, communication is a means of sending and processing information or ideas through a medium (message) which is both acceptable and familiar to the sender and the receiver. It follows that there must be shared understanding between the sender and the receiver for effective communication to take place.

Devito, cited in Otagburuagu (2009), posits that 'communication is the act by one or more persons, of sending and receiving messages undistorted by noise within a context with some effect and some opportunity for feedback'. This definition stresses the contextual nature of communication which elicits feedback or responses from the receiver as it is intended by the sender.

Similarly, Wood (1997) defines communication as a systematic process in which individuals interact with one another through symbols to create and interpret meaning.

Communication is, therefore, key to human interaction and understanding because meaning is so pivotal in every communication that the sender and receiver must operate at the same level of meaning. If there is a distortion at this level of message transmission, breakdown in communication becomes inevitable. This explains the complementary role played by body language amongst language impaired students in order to aid them to transmit ideas or information to their teacher or colleagues in a classroom situation. The receiver in turn is expected to send appropriate feedback to the student to show that effective communication has taken place.

Communication is subdivided into verbal and nonverbal communication. Verbal communication refers to the form of communication involving the use of words whether spoken or written. This form of communication is essentially linguistic and is generally the use of words or speech to express feelings, thoughts and emotions, as well as other interactional uses in society. Nonverbal communication on the other hand describes the process of conveying meaning in form of non-word messages such as facial expression, eye contact, gestures, body posture, proximity, et cetera. Gordon and Druckman (2018:93) posit that 'nonverbal acts serve to regulate conversation flow between people. Regulators are often culture -specific and may be subtle indicators to direct verbal interaction such as head nods, body position shifts and eye contact...'

Nonverbal communication is gestural in nature and can convey different meanings across different cultures. This makes shared understanding an important element for effective communication in this context. For example, one may strike his forehead to recall something, but in another culture it may be taken that one is not mentally sound; therefore, the sender and the receiver must be at the same level of meaning to achieve a mutual interpretation of the message. According to Robert Phipps (2012:18), 'Nonverbal is not just as it sounds; an unspoken message that has meaning behind it. By systematically breaking down these types of messages, you will learn to read people and situations better, improve the results you achieve and benefit from the ability to decode what is really going on around you'. Similarly, Susan Quillan (2008) opines that unspoken language shows us how to interpret the signals we receive and how to control the message we send.

Ultimately, the importance of nonverbal communication cannot be over- emphasized since much of human communication is done without words. Hogan (2010:14) summarises this in these words 'the reality is that nonverbal communication is part of everything you do everyday. Your personal nonverbal communication influences everyone around you... and theirs influences you'. 


\subsection{Language}

Language is generally a medium for human communication which is transmitted and patterned to embed human social experience. In the Outline of Linguistic Analysis, Block and Trager (1942:5) define language as 'a system of arbitrary vocal symbols by which a social group cooperates'. Babara and Strang (1969) view language as a set of human habits, with the purpose of giving expression to thoughts, and feelings; and to impart it to others. Fromkin et al. (2003) succinctly define language as the source of human life and power. These definitions of language, point to the indispensability of language in human life. Linguists claim that language is a significant criterion that distinguishes man from animals. Whereas animals can also communicate amongst themselves, language- vocal symbols -is exclusive for humans. As in any other social setting, language is used for social interaction amongst students and between students and their teacher in a learning environment. Obviously, language impaired students experience difficulties in the use of language amongst their peers, which can negatively affect their self-concept, confidence and personality in the learning process. This is the vacuum that body language tends to fill in this work.

\subsubsection{Body Language}

Body language is a formal area of study which first emerged in the 1950s and saw an exponential growth in the 60s.In later years, the focus of this study shifted from body language as a separate action with a single meaning to a complex aspect of communication where specific actions often have different meanings, depending on context, environment, culture and individual personalities (Hogan, 2010).

Body language refers to a non-verbal, physical behaviour used in the conveyance of information as opposed to words (https//en.m.wikipedia.org). The state of mind is exposed in language and certain body postures give clues to speaker intentions such as facial expressions, body postures, gestures, eye contacts, etc. People may have control over their words but body language is more instinctive and natural.Wikipedia.org also differentiates between signs and body language; viewing signs as having their own complex grammatical systems with funder mental language properties unlike body language that does not have a grammatical system and involves broad interpretations.

Haya, cited in Alibali et al. (1999), asserts that 'Not all of our values, beliefs, thoughts and intentions are communicated verbally. In an ongoing communication, most of those are communicated non-verbally. In nonverbal communion, our body expresses our feelings and intentions through conscious and unconscious movements and postures, accompanied by gestures, facial expressions, eye contacts and touch. This collectively forms a separate language of the body within an ongoing communication. This is called 'body language'.

Furnham \& Petrova (2010:23) opine that body language is made up of various signals: the quick glance, the wry smile, the well-known gestures, body postures.... Each, alone and together can provide a powerful and subtle form of communication to complement the spoken language.'

It is pertinent to state that body language can be interpreted differently by people, depending on the context. Thumbs up for one culture may mean a sign of victory; and a form of greeting for another. Interpretation on the use of body language, therefore, must be contextualised to avoid misinterpretation and message distortion in the communication process.

Patel (2014) posits that 'body language is a significant aspect of modern communication and relationships. Body language describes the method of communicating using body movements or gestures instead of, or in addition to verbal language. Body language includes subtle, unconscious movements, including winking and slight movements of the eye brows and other facial expressions.'

Patel (2014) further elaborates on body language in these words: 'Different researches were carried out on the role of body language and it has been reported that during communication: (1) only $7 \%$ of the information humans transmit to others is in the language we use; (2) $38 \%$ in how people speak -quality of voice, accent, voice projection, emphasis, expression, pace, volume, pitch, etc.; and (3) $55 \%$ through body language -posture, position, eye contact, facial expression, head and body movements, gestures, touch, etc.'

In the teaching and learning situation, much of the body language involve the use of facial expressions, eye contacts, gestures with the head, hands, shoulders and legs, which can be easily deciphered by the teacher or the receiver in the learning context. For example, nodding could mean acceptance or understanding of the message, while shaking of the head could signal misunderstanding and insufficient knowledge of the subject matter. Similarly, facial expressions such as a smile mean conformity and acceptance, whereas a frown could spell displeasure or stress. 
Goldin-Meadow (2004:539) opines that 'speakers' gestures can reveal knowledge that they have but cannot yet articulate... so a close examination of students' gestures may offer insights into students' conceptions not available from the transcriptions of their utterances'.

Similarly, a close look at the students, especially the language impaired, will give the teacher some clues that will help him/her deduce their emotional dispositions within the classroom setting and offer necessary assistance towards their learning efforts.

\subsubsection{Types of Body Language}

There are different expressions of body language.

i. Facial expressions: These are "behavioural 'expressions on the face that give insights on the attitude, emotions, intentions of the speaker or receiver in the communication process. Such facial expressions could be a smile, frown, a sneering or snarling look or a raised eye brow. The face is seen as the index of the mind because much of bodily emotions are transmitted through the face - emotions of fear, joy, sadness, displeasure, suspicion, love, uncertainty and the like are easily revealed through facial expressions. Illustrating the dynamic features of facial expressions, Patel (2014) asserts that 'A teacher might ask the student if he understood an idea, but he need not wait for an answer. A lacklustre bewildered facial expression would reveal that the student has not grasped anything'.

ii. Body gestures: Generally, gestures made unconsciously offer clues towards understanding the mental state of the speaker. For example, scratching the nose or twisting the shirt buttons are signs of lack of confidence; fidgeting suggests nervousness and fear. These are obviously visible to the receiver of the message. However, other gestures are open to different interpretations, especially when they are consciously initiated. A clenched fist may elicit different interpretation across cultures - for an American, it could mean emphasis but could be disrespectful for an Indian (Patel, 2014:92-3). Pearse and Pearse (2005) posit that 'each gesture or movement can be a valuable key to an emotion a person may be feeling at a time'.

Though certain bodily gestures are culture bound, others are universally accepted; waving means goodbye or a sign of affinity with a team, etc. In the learning situation, movements of hands and fingers can facilitate communication, especially amongst language impaired students. A turn of the finger by the student could signal to the teacher to repeat an expression made earlier for the student to understand. Similarly, a raise of the right hand suggests that the student wishes to answer or ask a question, as the case may be. The dexterity of the teacher towards recognising and interpreting bodily gestures goes a long way to facilitating the teaching and learning process, especially amongst speech impaired students.

iii. Eye Contact: The eyes play a significant role in displaying emotions. Frequent eye contacts or gazing at someone could mean expression of interest or a betrayal of honesty on the part of the sender. A wink could send a lot of messages to the receiver without much word because eye contact is discernable to the receiver in virtually all cultures, to mean an expression of affection or interest. However, Pearse and Pearse (2005) opine that 'modern humans are worse at reading body signals than their ancestors because we are now distracted by words'. The use of eye contact can also be applied to the learning environment by the student or the teacher especially if either of them aims at passing a 'coded' message 'away from jeering students', so as to avoid embarrassing situations that could affect the self- concept of a disabled student (Ezeh, 2014).

iv. Body postures: Body postures refer to the position of the speaker's body during communication. Body postures are stable in position, compared to body gestures which involve movements. For example, crossing one's legs is a posture, as against scratching the nose which is gestural in nature. A crossed leg suggests an informal situation unlike when a speaker is standing erect which suggests a degree of formality. The teacher can also deduce a student's emotional state from his/her body posture. A student who sits sagging in the seat could reveal a feeling of depression or boredom with classroom activities (Pearson et al., 2005). This helps the teacher to know when to introduce games and other fun activities to retain the interest of the student.

v. Proxemics: Space is another important type of body language. Proxemics implies the allowance of personal space or reasonable proximity between the speaker and the receiver in the communication process. According to Hall (1966) who introduced it, 'proxemics is the study of measurable distances between people as they interact with one another'. Hall came up with four distinct zones in which humans operate in communication as follows: the intimate distance; personal distance; social distance 
and public distance. These are degrees of distancing between the sender and receiver in communication. $\mathrm{He}$, however, states that physical contact/proximity range as in other types of body language varies with culture. For example, Latin Americans greet one another by kissing while North Americans prefer to shake hands. Proxemics can also be used in the classroom environment. The student may wish to come close to the teacher to whisper some sensitive information which other students may not be privy to. This manner of communication avails the students, especially the 'disabled' ones; the opportunity to express their views freely without being 'harassed' thereby boosting their self confidence in the learning process.

vi. Haptics: This refers to the act of touching to express certain ideas or emotional state. Haptics like handshakes, high fives or pats send certain information from the sender - extension of friendship, acknowledgement of praise and admiration - to the receiver. In the learning situation, haptics such as high fives and handshakes could be used by the teacher to motivate or reward a student's good performance in class.

vii. Voice tone: This can also be a form of body language. The manner in which something is said can either motivate or discourage the listener. A soft tone is inviting, just as a hoarse voice tone is scary. The teacher should be able to discern when to use a soft tone to encourage and a hoarse tone to condemn vices and correct students in a learning environment.

\subsection{Language Impairment}

Language impairment is the disability to understand and /or use words in context, both verbally and non-verbally. Such disabilities include improper use of words and their meanings, inability to express ideas, inappropriate grammatical patterns, reduced vocabulary and inability to follow directions. One or any of the combinations of these disabilities may affect a child's development of language proficiency in the learning situation (Prozesky, 2000). Worse still, the child may also experience difficulty in understanding his peers in the process of communication. Therefore, interventions for specific language impairment will depend on individual disability. For example, the problem of comprehension will attract interventions that are geared towards developing metacognitive strategies in evaluating the child's knowledge within the communication process, such as the use of probing questions and repetitions on the part of the teacher. However, much of language impairments are linked to environmental causes such as insufficient language stimulation in the environment. Also autism and other neurological disorders may also lead to language impairment.

\subsection{Speech Impairment}

This is an aspect of language disorder that involves impaired ability in producing speech sounds which may be mild or severe articulation disorders characterised by omission or distortion of speech sounds, a fluency disorder involving rhythm and repetition of sounds or a voice disorder characterised by abnormal pitch, volume, resonance, vocal quality or duration (http://speech pathology australia.org.au/alternative communication).

Articulation disorders may be considered natural at a tender age when children are learning to talk but when the child passes that developmental stage and is unable to produce speech sounds accurately, he/she is seen as being speech impaired. For example, where a child produces sound incorrectly -sounds like 1 or $r$ - the sounds may be left off, changed or distorted, making it difficult for others to understand the child (Okorafor, 2014). Other types of speech impairment include fluency disorders, also known as dysfluency which is characterised by stuttering or interruption in normal speech flow and false starts; as well as voice disorders. Voice disorders could manifest in abnormal quality in pitch, resonance and loudness of voice, resulting in hoarse, raspy or harsh voice.

The teacher needs to be proactive in devising learning strategies such as voice modulation aids in complementing the child's speech abilities. More importantly, the teacher must exercise class control to block undue harassments from other children, to assist the child in maintaining a positive self-concept within and outside the classroom environment.

\subsection{Applying Body Language in Teaching and Learning English as a Second Language}

In an ESL context, students who suffer language/speech impairment, face challenges in communicating effectively with their classmates and teachers. In understanding and giving oral presentations in the teaching and learning situations, the teacher primarily needs to boost the self-confidence of the impaired students by encouraging them to use body language to complement their language expressions; and in turn employing certain pedagogic strategies that involve facial and gestural expressions to drive home his teaching. The use of body language, especially those involving the hands, face, and body movements, is very beneficial for effective 
communication. For example, the nodding of the head could suggest understanding of an idea by the student, as against shaking the head to show lack of understanding.

Also, most disabled students feel out-of-place in a normal learning situation. They feel that they are not on the same page as the 'able' students and the feeling of inadequacy and inferiority becomes inevitable. The teacher has the responsibility to assist these language impaired students to come out of their shelves through the use of appropriate body language and to help them to assert their unique individualities in the learning process. The use of body language will help in attaining normalcy within the group of learners.

Generally, the teacher plays the role of a motivator in the teaching and learning process, especially amongst language/speech impaired students. To bring out the best in these special learners, he must be patient, with an exceptional listening skill. Pearse and Pearse (2005) opine that the key to reading body language is being able to understand a person's emotional condition while listening.

Essentially, the teacher has these specific roles to play in the learning process:

i. To show empathy towards the feelings and attitudes of the learners and avoid providing words or finishing sentences for stuttering students. The creation of opportunities of participation by the teacher is a significant step towards inclusive learning amongst language impaired students.

ii. Encourage students' participation in classroom activities.

iii. Augmenting their speech abilities with the appropriate body language as well as such learning tools as laptop speech synthesizers, signboards or sign interpreters in the ESL context.

iv. Be frank with his opinion on the student's performance, not being pretentious but having the courage to allow the student to know when he is required to explain, where he is not understood.

v. Encourage their use of sign language to achieve clarity in message delivery. The use of hand movements in language expressions, complement speech impairment; helping impaired students to reduce frustration and behavioural difficulties.

vi. The use of other appropriate body language such as handshakes, clapping which also help the students to develop complex thinking skills because the need to be rewarded or acknowledged awakens their thinking abilities.

\section{Area Description}

The study was conducted in three higher schools in Enugu metropolis, Nigeria; in an English language teaching and learning context. The age of the students falls between 10-16 years. This population was deliberately selected to accommodate both cadres of junior and senior students in the schools. The research assessed the benefits of using body language in the classroom, amongst the students and between the teacher and the students. The survey prioritised on the language impaired students who obviously experience communicative deficiencies by virtue of their language disabilities. The use of body language as a communicative aid amongst these students attempts to complement other pathological and speech intervention efforts in the educational sector in Nigeria. Body language is considered to be a more natural phenomenon amongst students, as well as a cost-effective measure towards improving learning abilities and ultimately, the communicative competence of students.

\section{Methodology}

The methodology of the study is quantitative, with the use of questionnaires for both language impaired students and their teachers, designed to capture their experiences in an ESL context. The use of body language and its effectiveness was discussed in teaching and learning in order to ascertain the usefulness of adopting body language in the classroom.

\subsection{Presentation of Task}

Questionnaires/verbal interviews were used to seek responses from language and speech impaired students in three higher schools in Enugu metropolis in Nigeria. Though the number of students with language impediments was small, a total of forty five students were sampled as well as fifty five teachers who have had the opportunity of teaching speech impaired students.

The questionnaires administered to the impaired students tested their use of body language in the classroom and how beneficial the body language is to them in the learning process. 
The teacher questionnaires sought to investigate the use of body language as a teaching aid by the teacher and to know the most appropriate and viable body language that brings out the best in language impaired students. The findings were in line with objectives of the research.

\section{Results}

5.1 Results on Students' Questionnaires

\begin{tabular}{|c|c|c|}
\hline Questions & Variables & Percentage \\
\hline \multirow[t]{2}{*}{ 1. How old are you? } & $10-14$ & $70 \%$ \\
\hline & 15 and above & $30 \%$ \\
\hline \multirow{2}{*}{$\begin{array}{l}\text { Do you consider yourself handicapped in language } \\
\text { or speech ability? }\end{array}$} & Yes & $100 \%$ \\
\hline & No & $0 \%$ \\
\hline \multirow[t]{5}{*}{ What type of disability do you have? } & Difficulty in pronouncing words & $70 \%$ \\
\hline & Difficulty in understanding others & $40 \%$ \\
\hline & Stuttering & $80 \%$ \\
\hline & Difficulty in expressing ideas & $80 \%$ \\
\hline & Others & $20 \%$ \\
\hline \multirow{2}{*}{$\begin{array}{l}\text { Does it affect your academic performance in the } \\
\text { classroom? }\end{array}$} & Yes & $96 \%$ \\
\hline & No & $4 \%$ \\
\hline \multirow{3}{*}{$\begin{array}{l}\text { What strategies have you used to improve your } \\
\text { language challenges? }\end{array}$} & Interacting with students & $30 \%$ \\
\hline & Gestures with hands /body & $50 \%$ \\
\hline & Language/speech aids & $20 \%$ \\
\hline \multirow{4}{*}{$\begin{array}{l}\text { Rate the effectiveness of this strategy in improving } \\
\text { your understanding in classroom instructions? }\end{array}$} & Body language & $60 \%$ \\
\hline & Language/speech aids & $20 \%$ \\
\hline & Laptop speech synthesizer & $10 \%$ \\
\hline & Others & $10 \%$ \\
\hline \multirow{5}{*}{$\begin{array}{l}\text { 7. What type of body language do you consider most } \\
\text { effective? }\end{array}$} & Hand and body movements & $50 \%$ \\
\hline & Facial expressions & $30 \%$ \\
\hline & Eye contact & $5 \%$ \\
\hline & Body posture & $10 \%$ \\
\hline & Others & $5 \%$ \\
\hline
\end{tabular}

In administering the questionnaires, it was discovered that most of the speech impaired students showed their unwillingness to respond because of their low self-esteem and fear of being mocked by their colleagues. However, the teachers helped in sensitizing these challenged students to respond to the questions to enable the school get better information to provide learning support for them. The result of the questionnaires showed the usefulness of body language in complementing classroom instructions and in their interaction with other students. The responses further confirmed the students' acceptance of body language as a viable communication tool in the teaching and learning process. 
5.2 Results on Teachers' Questionnaires

\begin{tabular}{|c|c|c|c|}
\hline \multicolumn{2}{|c|}{ Questions } & \multirow{2}{*}{$\begin{array}{l}\text { Variables } \\
\text { Yes }\end{array}$} & \multirow{2}{*}{$\begin{array}{l}\text { Percentage } \\
100 \%\end{array}$} \\
\hline 1 & Do you have language/speech impaired students in your class? & & \\
\hline \multirow{4}{*}{2} & \multirow{4}{*}{ How many of them? } & No & $0 \%$ \\
\hline & & $1-5$ & $100 \%$ \\
\hline & & $6-10$ & $0 \%$ \\
\hline & & 10 and above & $0 \%$ \\
\hline \multirow[t]{2}{*}{3.} & \multirow{2}{*}{$\begin{array}{l}\text { From your observation, do you think that their language } \\
\text { handicap affect their understanding and performance in class? }\end{array}$} & Yes & $100 \%$ \\
\hline & & No & $0 \%$ \\
\hline \multirow[t]{4}{*}{4.} & \multirow[t]{4}{*}{ In what ways? } & Stuttering & $60 \%$ \\
\hline & & $\begin{array}{l}\text { Lack of understanding } \\
\text { of class instructions }\end{array}$ & $50 \%$ \\
\hline & & $\begin{array}{l}\text { Difficulty in interacting } \\
\text { with others }\end{array}$ & \multirow{2}{*}{$70 \%$} \\
\hline & & $\begin{array}{l}\text { Difficulty in expressing } \\
\text { ideas }\end{array}$ & \\
\hline \multirow[t]{3}{*}{5} & \multirow{3}{*}{$\begin{array}{l}\text { What teaching strategies do you adopt in facilitating } \\
\text { understanding and performance amongst language impaired } \\
\text { students? }\end{array}$} & Language aids & $30 \%$ \\
\hline & & Body language & $60 \%$ \\
\hline & & Others & $10 \%$ \\
\hline \multirow[t]{6}{*}{6} & \multirow[t]{6}{*}{ What type of body language? } & $\begin{array}{l}\text { Hands and body } \\
\text { movements }\end{array}$ & $50 \%$ \\
\hline & & Haptics & $40 \%$ \\
\hline & & Facial expressions & $40 \%$ \\
\hline & & Proxemics & $20 \%$ \\
\hline & & Eye contact & $30 \%$ \\
\hline & & Body postures & $35 \%$ \\
\hline \multirow[t]{3}{*}{7.} & \multirow{3}{*}{$\begin{array}{l}\text { Rate the effectiveness of body language in your interaction with } \\
\text { students? }\end{array}$} & Less than $40 \%$ & $15 \%$ \\
\hline & & $40-70 \%$ & $25 \%$ \\
\hline & & $70 \%$ and above & $60 \%$ \\
\hline
\end{tabular}

The responses from the teachers' questionnaires showed their experiences in handling language disabilities and the indispensable role of body language in the teaching and learning process. Most of the teachers admitted using body language in their interaction with their students in spite of other pathological and speech support aids at their disposal. Body language comes so natural to the sender and the instincts are easily visible and interpretable to the receiver. This applies to classroom interaction between the teacher, language impaired students and their colleagues.

Essentially, the responses received from teachers' questionnaires confirmed the viability of body language as an effective communicative tool in the teaching and learning context.

\section{Discussion of Findings}

The result of the quantitative survey conducted on the viability of body language in the teaching and learning context revealed the indispensable role of body language as a communication tool in the classroom. Body language is an incentive for both the teacher and the students in the conveyance of ideas, emotions and in the transmission of knowledge. Deductions from the responses in the two sets of questionnaires received showed that hands and body movements (gestures) and facial expressions are more effective body language in order of importance, than other types of body language in the classroom environment. For example, a clap or a handshake is a sign of reward or acceptance for a positive behaviour which motivates the students. A frown could suggest lack of understanding or boredom by a student, just as it could mean displeasure from the teacher about a 
student's conduct; hence these body languages are easily interpreted and reacted to accordingly in the teaching and learning process. Ultimately, the results addressed the aim of the study by affirming the great significance of body language in communication, especially in the ESL context.

\section{Conclusion}

Body language is an unconscious activity that adds value to the communicative process, especially in the teaching and learning of English language as a second language. Physical factors and other health conditions that affect nerves and muscles as well as damage in the part of the brain that deals with communication can led to language and speech impairments amongst students in a learning situation. This may result in the loss of speech, increase in language difficulties, dysfluency, lack of experience stimulation and limited opportunities to interact with others. The study was able to establish the significance of the use of body language in developing and complementing language abilities towards a stimulating and rewarding learning experience, both on the part of the teacher and students.

\subsection{Limitation to the Study}

The poor self-concept of most of the language impaired students affected their willingness to candidly respond to the questionnaires for fear of being mocked by their colleagues.

Additionally, in some of the schools, the language impaired students were few in number, making the number of questionnaires administered inadequate.

\subsection{Future Research}

The following areas were identified in the course of the study for future research:

i. Sensitisation of teachers on the adoption of appropriate teaching and learning strategies especially amongst handicapped students. A significant number of students are physically challenged, hence the need for teachers to be trained on these strategies so that they will be better equipped to handle disabilities amongst students and provide them with a rich learning experience.

ii. There is the need to incorporate the challenges of disabled students in educational planning in Nigeria. Most educational programs do not address the needs of the physically challenged. Educational planners should take cognisance of this fact and amend the policies to make education more inclusive in the society.

iii. Physical disability does not imply mental retardation. In fact, researches have shown that most physically challenged individuals exhibit a high level of mental alertness if given the right stimuli. There is the need for a study to assert this fact, to bring about a reappraisal of their social status and ultimately, accord them better treatment in the Nigerian society.

\section{References}

Alibali, M. et al. (1999). Illuminating mental representations through speech and gestures. Psychological Science, 10(4), 327-333. https://doi.org/10.1111/1467-9280.00163

Babara, M., \& Strang, H. (1969). Modern English structure. London: Edward Arnold Ltd.

Bloch, B., \& Trager, G. L. (1942). Outline of linguistic analysis. Linguistic Society of America, Philadelphia: Baltimore.

Ezeh, N. G. (2014). Deixis and its implication for communication: A study of speeches and informal conversations. Unpublished Thesis, NnamdiAzikiwe University, Awka, Nigeria.

Fromkin, V. et al. (2003). An Introduction to Language. (7th ed.). New York: Micheal Rosenbury.

Furnham, A., \& Petrova, E. (2010). Body language in business: Decoding the signals. London: Palgrave. https://doi.org/10.1057/9780230292291

Goldin-Meadow, S. (2004). Gesture's role in the learning process. Theory intoPratice, 43(4), 314-321. https://doi.org/10.1207/s15430421tip4304_10

Gordon, R., \& Druckman, D. (2018). Nonverbal behaviour as communication: Approaches, Issues and Research. Routledge. https://doi.org/10.4324/9781315436135-4

Hall, E. T. (1966). The hidden Dimension. New York: Doubleday.

Hogan, K. (2010). The secret language of business: How to read anyone in 3 seconds or less. USA: Wiley. 
https://en.m.wikipedia.org- body language

https://speech pathology australia.org.au/alternative communication.

Hybels, S., \& Weaver, R. (1998). Communicating effectively. USA: McGraw Publishers.

Okorafor, D. (2014). Basic oral English and common mispronunciations. Enugu: Ice Canopy Ltd.

Otagburuagu, E. J. (2009). New perspective in business communication. Onitsha: Book House Trust.

Patel, D. (2014). Body language: An effective communication tool. The IUP Journal of English Studies, IX(2).

Pearse, A., \& Pearse, B. (2005). The definitive book of body language. UK: Orion Publishing group.

Pearson, J. et al. (2005). Human communication. Boston: McGraw Hill Publishing.

Phipps, R. (2012). Body language: Its what you don't say that matters. USA: Wiley.

Prozesky, D. R. (2000). Communication and effective teaching. Journal of Community Eye Health, 13, 44-45.

Quillan, S. (2008). Body language. London: Carlton books.

Rurthrof, H. (2015). The Body in language. UK: Bloomsbury.

Verderber, R., \& Verdeber, K. (2005). Communicate. China: Thomson Wadsworth.

wiki/comunication.org.

Wood, J. T. (1997). Communication in our lives. UK: Wordsworth Publishing.

\section{Copyrights}

Copyright for this article is retained by the author(s), with first publication rights granted to the journal.

This is an open-access article distributed under the terms and conditions of the Creative Commons Attribution license (http://creativecommons.org/licenses/by/4.0/). 